\title{
Understanding the Role of Rural Entrepreneurs in Telecentre Sustainability: A Comparative Study of the Akshaya and eSeva Projects in India
} Gaurav Mishra and Balakrishnan Unny R

\author{
"We all of us need assistance. Those who sustain others") \\ themselves want to be sustained.
}

Maurice Le Sage d'Hauteroche d'Hulst (1841-1896)

Priest, writer, and orator

In The Way of the Heart

\begin{abstract}
In rural areas of India, telecentres provide access to computers and other digital technologies and have been utilized as a delivery channel for various government services. Following a public-private partnership (PPP) model, there is a general belief among policy makers that the revenue from government-to-consumer (G2C) services would be sufficient to cover the village-level entrepreneurs' cash flow requirements and therefore provide financial sustainability. Also, the literature suggests that telecentres have a large enough market for public-access businesses to be commercially viable. In India, around 100,000 telecentres are being set up to serve 600,000 villages - one telecentre for every six villages - to provide one-window access to government services. In the literature, a lack of government services is often quoted as a reason for telecentre failure. This study, using an exploratory approach, aims to understand the parameters that relate to the sustainability of telecentres across a number of common, government-related services. It is observed that some telecentres perform better than the others even though they have the same number of government-related services. Reasons for such differences are explored and the learnings from this research will benefit the stakeholders who are engaged in providing telecentre-based services in other developing countries. In addition, a theoretical framework is suggested to understand the dynamics between different types of sustainability parameters such as financial, social, staff, technology, and institutional. The findings of this research have policy implications in terms of the way services are designed and delivered through telecentres in developing countries such as India.
\end{abstract}

\section{Introduction}

Information and communication technologies (ICTs) are hailed as important tools for rural development and are considered essential for enhancing livelihoods of people in rural areas (Gilbert et al., 2008). According to Geldof and Unwin (2005), ICT can be used as a tool for strengthening education, improving public services and governance as well as for supporting agriculture and the service industry. Telecentres are seen as one of the most successful means to promote ICT diffusion in developing countries because they increase the access of ICT to people, particularly the poor people living in remote rural areas (Gopakumar, 2006).

Roman and Colle (2002) define a telecentre as a public place where people can access a variety of communication services. However, telecentre implementations in developing countries have not always been successful. In addition, there is not much research on the cause of collapse of telecentres though sustainability of telecentres is a key issue debated surrounding the use of ICT-enabled projects in developing countries (Harris et al., 2003; Sigweni et al., 2017). 


\section{Understanding the Role of Rural Entrepreneurs in Telecentre Sustainability}

Gaurav Mishra and Balakrishnan Unny R

In India, there is a lot of emphasis put on the implementation of telecentre-based projects given the opportunities they provide to rural citizens. For example, in the Government of India's National e-Governance Plan (tinyurl.com/y8twn3w8), with a commitment of around one billion dollars, 100,000 telecentres are to be established in rural areas to improve service delivery to citizens and businesses (IIITB, 2005; Mukerji, 2008). These telecentres are implemented based on the public-private partnership (PPP) model and mainly for-profit organizations. Under this model, public organizations provide a suite of services and other necessary support to telecentres. The entrepreneurs are supposed to invest, maintain, and operate the telecentres. In this model, the PPP is a contractual agreement between the government and a village-level entrepreneur to supply infrastructure assets or services for telecentres, which are known as "common service centres" under the National e-Governance Plan. The government is responsible for managing the implementation of the project and providing e-government services such as application forms, income and caste certificates, and utility payments such as electricity, telephone, and water bills. Within the national plan, the aim of the Common Service Centre Scheme is to establish one common service centre for every six census villages. The Government of India envisages common service centres, or telecentres, as integrated front-end delivery points for services from the government, the private sector, and the social sector for the rural citizens of India. Through a social development approach, telecentres intend to help individuals and communities to address social needs of the disadvantaged and excluded less-resourced majority of a community. However, the said approach generates considerably high social capital since it is community driven, but it is weak on financial sustainability (Meddie, 2006).

\section{Problem statement}

Much literature is available on studies of telecentres in India. For example, Bhatnagar (2003) analyzed the effectiveness of the Bhoomi project, whose aim was to computerize land records and to reduce corruption with respect to the land records of farmers in the state of Karnataka, India. He concluded that there was a decrease in corruption as the project reduced the discretion of government officials by the introduction of an online form to request alterations to land records upon their sale or inheritance.

For village-level entrepreneurs, the sustainability of telecentres is crucial because their livelihoods depend on them. However, the literature defines several types of ICT sustainability, namely: financial, technological, social, institutional, and staff. Financial sustainability refers to the capability of telecentres to earn sufficient income for ongoing maintenance and operation. Technologically sustainability ensures that any change in technology does not affect the availability of products and services through telecentres (Misund \& Hoiberg 2003), and technological sustainability is therefore related to financial sustainability (Kuriyan \& Toyama, 2007). A socially sustainable telecentre is able to meet the service needs of citizens. Institutional sustainability is the relationship of ICT-enabled projects to various public and private institutions for services, infrastructure, support, etc. Staff sustainability refers to the continuous availability of skilled staff for telecentres; it is the capacity or extent to which trained people, or their trained replacements, continue to work on the same project.

Policy makers believe that the revenue from government-to-consumer (G2C) services would be sufficient to cover the operator's cash flow requirements. Also, the literature suggests that telecentres have a largeenough market for public access businesses to be commercially viable. However, a lack of financial sustainability is often seen as the cause of telecentre failure. However, other types of sustainability are also discussed in the literature on telecentres, such as social (Tschang et al., 2002); technological (Proenza, 2001); institutional, staff, and environmental (Harris et al., 2003); political (Pade et al., 2006); and service-related (Rao, 2008).

Moreover, many models define the evolution of entrepreneurial ventures (e.g., Levie \& Lichtenstein, 2010; Morelli, 2003; Rao, 2008) may be applicable. According to Fuchs (1998), telecentres follow product lifecycles, and throughout the life of telecentre development and establishment, it is important for the entrepreneurs to adopt and follow the principle of "demo or die". When the demonstration does not work, it is important to understand why and take appropriate steps to make sure that the telecentre does not then die due to recurring errors. Indeed, telecentre-based projects that are located in poor rural areas might have to be self-sufficient by the end of the project lifecycle (Mercer 2005). Hence, we have to understand the telecentre evolution in the light of a product lifecycle. In addition, we also need to understand the factors influencing the sustainability of telecentres at different stages of evolution, from their introduction, growth, and maturity to their decline. However, there is limited understanding of 


\section{Understanding the Role of Rural Entrepreneurs in Telecentre Sustainability}

Gaurav Mishra and Balakrishnan Unny $R$

how different types of sustainability parameters are related to the stages of telecentre lifecycle and how they are interrelated.

Through this study, we attempt to provide a theoretical framework to understand the dynamics between different types of sustainability parameters - including financial, social, staff, technological, and institutional - and relate them to the stages of the telecentre lifecycle. Based on literature review, the authors are of the opinion that these five sustainability parameters are crucial to the running of telecentres. Thus, due to time and resource constraints, we have limited our scope to only these five sustainability parameters. However, in future, we intend to address other sustainability parameters of telecentres. In addition, we try to identify the roles of telecentre stakeholders at different growth stages. The overall objective of this study is to draw lessons that would help in improving the sustainability of telecentres throughout their evolution.

\section{Research Methodology}

A social constructivist epistemological position is taken for the research. The basic idea behind constructivism is that reality does not exist objectively, rather it is constructed by human beings subjectively. According to Madon (2004), a constructivist approach is most common in interpretive case studies. The telecentres movement is seen as an innovation in rural areas and, according to Gaiani and colleagues (2009), important factors affecting the use of innovations can be identified using a constructivist approach whereby each person is seen as a unique individual with unique peculiarities and backgrounds. There is lack of information on the critical sustainability issues affecting the development of ICT-based projects in rural communities (Meng et al., 2013); therefore, we took an exploratory approach. An exploratory approach is suitable where little information exists regarding the workings and impacts of the programs under study (Barkley, 2006).

We collected the data using qualitative methods, including focus groups and semi-structured interviews. Qualitative methods of data collection helped us answer the "why" and "how" part of the problem statement.

For the study, we selected two projects in rural India: the Akshaya project (Box 1) in the Kollam and Mallapuram districts of Kerala and the eSeva project (Box 2) in the West Godavari district of Andhra Pradesh.
Both have been running for more than five years, meaning they can provide greater insights on sustainability than relatively newer ones. In addition, the projects also provide a number of e-government services, which provides an opportunity to study diverse services and their delivery.

We selected study subjects on the basis of convenience sampling due to time and resource constraints (Table 1). In addition to holding a focus group for each project, we interviewed 50 entrepreneurs and 4 government project officials from the Akshaya project and 28 entrepreneurs and 3 officials from the eSeva project.

The sample size was deemed appropriate for the study because we stopped interviewing new respondents at a point where no new value-driven information was being provided. A greater number of entrepreneurs than

Box 1. The Akshaya project (tinyurl.com/yclfnxr5)

The Akshaya project aims to address the issues of ICT access, basic skill sets, and availability of relevant content and government services in rural areas of Kerala, India. The project was launched in November 2002 in the Malappuram district of Kerala as a pilot. Its goal was for at least one person in every family in the district to be computer literate. Based on encouraging results, the project was rolled out throughout the state of Kerala in 2004. The main services provided through Akshaya centres are e-payment of utility bills such as electricity, water, and telephone bills. In addition, traders and business can file their sales tax returns in Akshaya telecentres. Citizens can also book train tickets through e-ticketing facilities. The Akshaya centres also provide technical education, mostly in computer software and hardware. However, they have spread their activities into other fields such as bioinformatics, medical transcription, and mobile communication. Keltron (keltron.org), an undertaking of the Government of Kerala, collaborated with the Akshaya project to provide a medical transcription course. The India Gandhi National Open University (ignou.ac.in) offers a distance education programme through the telecentres in areas including art, science, social science, and information technology, and the fee structure is such that the courses can be afforded by the disadvantaged sections of the society. 


\section{Understanding the Role of Rural Entrepreneurs in Telecentre Sustainability}

Gaurav Mishra and Balakrishnan Unny R

officials were chosen for the interviews because they are central to telecentre sustainability. The government has provided a platform for the entrepreneurs to earn revenue through telecentre services. The entrepreneurs belong to the local communities, and therefore, they provided rich data on how the local context and their actions have influenced sustainability parameters at different stages of their evolution. Project officers were useful in providing details of project implementation, service roll-out, and other related aspects of the project sustainability. Table 1 provides an overall profile of the respondents across both projects.

We used grounded theory coding for the analysis because it is useful in studies of comparatively unexplored areas (Samik-Ibrahim, 2000). Also, given that the focus of the study is to build theory, grounded theory helps to explain, at a broad conceptual level, a new and unexplored process, action, or interaction about a phenomenon (Creswell 2002). Thus, we qualitatively examined the texts from the interviews, field notes, and relevant documents by means of basic coding and interpretive analysis. The texts were then analyzed to identify relationships, themes and patterns in the discourses regarding how they related to the research objectives. The qualitative responses of the respondents were analyzed by developing theoretical categories from the data, which helped in analyzing relationships between key categories (Charmaz, 1990). We used both predefined codes from our literature review of telecentre sustainability (e.g., social sustainability, technology sustainability) and custom codes. Each piece of content was analyzed at an individual level and then compared across participants to identify patterns and common categories.

Table 1. Overall profiles of the study subjects (i.e., entrepreneurs and project officials) from the Akshaya and eSeva projects

\begin{tabular}{ll}
\hline Parameter & Details \\
\hline Average Age & 27 years \\
\hline Education & $\begin{array}{l}70 \% \text { have a graduate degree } \\
10 \% \text { have a post-graduate degree } \\
20 \% \text { do not have any degree }\end{array}$ \\
\hline Average Annual Income & Rs. 200,000 (approx. \$4000 CAD) \\
\hline Gender & $80 \%$ male; $20 \%$ female \\
\hline
\end{tabular}

\section{Box 2. The eSeva project (esevaonline.ap.gov.in)}

The objective of the eSeva project is to provide vital information that was formerly inaccessible to citizens in rural areas at the click of a button and therefore this project is described as "citizen centric". The project regards information as a crucial for bringing about a change in human lives. ICT is deployed for bridging the gap between citizens and government. The project was initiated by government in the West Godavari district of Andhra Pradesh. The major focus of the project was to provide government-to-citizen (G2C) and customer-to-customer (C2C) services in rural areas. To provide these services, 150 telecentres were opened in the district in 2003. The main services available when launched were:

- online filing of complaints and grievances: citizens had the option of making a complaint against any government official and were able to hold government officials accountable

- online application registration: the centres enabled web citizens to apply online for any government scheme, for example, a loan towards self-employment or an old age pension)

- issuance of certificates (e.g., from government related to nativity/residence, income, and caste)

- issuance of land records (e.g., farmers could apply for the latest land-related documents, register a change in land title)

- online auctions and bidding

- payment of dues/utility bills

- access to information related to government contact details, police station, hospital, fire station, etc.

- matrimonial services for prospective brides/bridegrooms

- online civil supplies allotment (e.g., to collect allotment orders online from the centre without having to "grease the palms" of government officials)

- tele-medicine/tele-agriculture/e-education and citizen forum (e.g., services for an online discussion forum to citizens through the portal for problems and issues in their locality, put ideas forward, etc.). 


\section{Understanding the Role of Rural Entrepreneurs in Telecentre Sustainability}

Gaurav Mishra and Balakrishnan Unny R

\section{Findings and Discussion}

Based on the qualitative analysis, we identified four stages in the telecentre lifecycle and their relationships with the different types of sustainability (financial, technological, social, institutional, and staff) (Figure 1).

First, there is the introduction stage, when the telecentre has been created in the rural area. In this stage, the participants felt that there is a need for extensive support from the government agencies as they are unaware of the regulatory requirements. Also, a speedy registration and approval process will help the telecentres. There is also a need for training to use the ICT resources of the telecentre. One of the entrepreneurs of the eSeva centre [ES14] said that, at the start of the project, government support ensured that an appropriate suite of services was available, but that frequent leadership led to the closure of around $90 \%$ of services. However, the Akshaya project started with just a few services available, including an e-literacy programme, and other services were added later. As stated by one
Aksaya respondent [AS34] noted: "When the e-literacy was programme was over, additional services like epayments were started". In addition, private players supported the centres with additional education-based services such as Intel Learn. Such support was not observed in the case of the eSeva project as "only e-payment services are active now" [ES21]. The government support in the initial and subsequent phases ensured a continuity of services. Therefore, in the initial stages, institutions have to do some handholding, which can be reduced as the telecentre matures and offers more services.

However, the role of the entrepreneurs is also important in the initial stages as they are mobilizers for creating trust in rural citizens towards the centre and its services. For example, during the first few months after setting up her telecentre, one entrepreneur [AS13] raised awareness by going door to door to tell people about the services available - even though she was known to most villagers. It is necessary to create trust in citizens in the early stages of a telecentre's lifecycle.

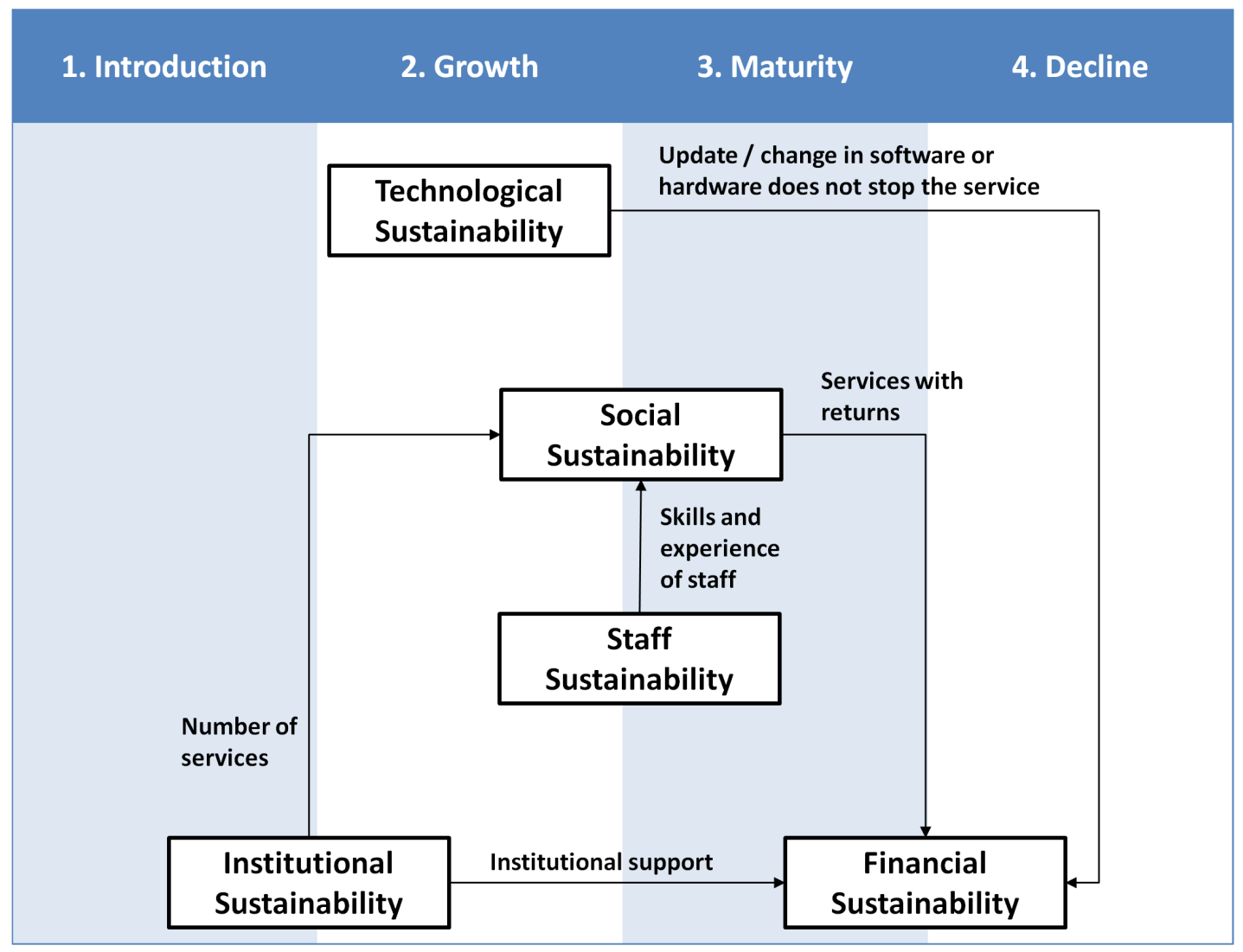

Figure 1. The key relationships between the different types of sustainability across the four stages of the telecentre lifecycle 


\section{Understanding the Role of Rural Entrepreneurs in Telecentre Sustainability}

Gaurav Mishra and Balakrishnan Unny $R$

Other innovative approaches used by entrepreneurs included talking about services at village level meetings, during religious gatherings, etc. Such social influence creates trust and motivates people to use telecentre services. It was observed that entrepreneurs who engaged with villagers on a consistent basis from the inception of their telecentres had greater footfalls.

The second stage in the lifecycle is the growth stage where the telecentre's benefits have been accepted by the public and thereby there is a rise in the use of the services. The participants felt that there are so many factors that may hinder the growth of the telecentre. The first factor is the disruption in the technology infrastructure. Any issues here will have a significant impact on the people's confidence in the technology, which they are just beginning to trust. As rural citizens do not directly interact with high technology, the role of entrepreneur/employee is very significant. Rural citizens were time conscious and expected prompt services. This promptness of service delivery is of value to people, and any shortcoming in service delivery will affect trust. Therefore, entrepreneurs have to ensure that they and their employees are aware of the technology usage. Also, it was observed that entrepreneurs who were skilled in handling hardware and software issues of both the computers and other related peripherals were often able to provide continuous, uninterrupted service, and thereby enhanced customer trust. Therefore, where entrepreneurs do not have such skills, they should maintain backup resources for smooth service delivery. The second factor is support from the community, which is vital at this stage. Many participants relied heavily on the support from community leaders to make the telecentre part of the community's daily activities. The participants also felt that their presence in local events helped in spreading awareness. Given that most of the telecentre entrepreneurs are from the local community, there was limited resistance from the public. At this stage, entrepreneurs should seek to provide additional services that might be relevant in the telecentres' social context. For example, an entrepreneur [AS12] noted that many people from his village went to the Persian Gulf for jobs, so he started offering UAE Exchange services in his telecentre to meet the demand for this particular money exchange. Similarly, a telecentre located in the panchayat (local village) provided the entrepreneur with the opportunity to develop service to provide all the necessary assistance to customers in filling in government application forms. Also, it was seen that services such as telephone bill payment were not relevant in some eSeva centres because there were no landline telephone facilities in many villages. Therefore, not only is a continuous flow of services essential for financial sustainability, but also relevant and socially acceptable services - customized to the local context - have to be provided.

The maturity stage is when the community has completely accepted the use of the telecentre. In this stage, the transactional services provide the major part of the revenue. Most eSeva entrepreneurs depend on e-payment services for the financial sustainability of their centres. They even go to villages to collect electricity bills using hand-held billing machines. There is constant flow of revenue from services such as utility bill payments. The number of customers at this stage is more or less constant. However, due to inflation, increase in rent, increment in the salary of operator, etc., the operational costs tend to increase over a period of time. Hence, entrepreneurs have to increase suite of services in addition to what is provided by government. Services may be added based on the social context as discussed earlier or they may collaborate with other private players for additional services. For example, some Akshaya entrepreneurs added medical transcription courses at their centres. In another instance, some centres included computer courses to enhance their revenue. The entrepreneurs who were not able to enhance their revenue struggled to meet operational expenses once their customer base became constant. Also, the participants noted that, in this stage, employee attrition is at the maximum, thereby putting a strain on the telecentre operations. To overcome this issue, some entrepreneurs engage youths of their own villages. Our data shows that operators who belong to the local community have been working in the centres for an extended period of time as they are averse to any relocation. The services provided up to the maturity stage are not observed to provide social development as the major emphasis of entrepreneurs is revenue generation. Though there were services that related to social capital in the earlier stages, entrepreneurs did not take interest in promoting those services due to lack of revenue generation capability of such services. At the maturity stage, some entrepreneurs started focusing on information-based services to enhance social sustainability. The underprivileged used the centres for various information services such as providing contact details of government officials, information on government schemes, etc. By doing, this the entrepreneurs felt that they were providing a service to society, and their reputations in their villages have increased.

The last stage in the lifecycle is decline. Many participants felt that this stage will be delayed as there are 


\section{Understanding the Role of Rural Entrepreneurs in Telecentre Sustainability}

Gaurav Mishra and Balakrishnan Unny R

more services being introduced by the government that will keep the telecentres in constant demand. An example of a new service is the Aadhar (foundation) card process, which was launched by the Unique Identification Authority of India (UIDAI) to provide unique biometric identity numbers to all residents of India. However, compared to Akshaya telecentres, eSeva telecentres have insufficient services for financial sustainability. eSeva entrepreneurs feel that there must be more financial support from the government to help make the telecentres sustainable. Although such a demand was not explicitly expressed by the Akshaya entrepreneurs, they expressed their need for continual training and support from the government.

\section{Conclusion}

The literature suggests that telecentres generally struggle and often fail to achieve financial sustainability. However, financial sustainability is associated with a number of factors including better management, strategic locations, local demand, new service development, locally relevant services, external linkages, and networking (Sey \& Fellows 2009). However, in this study, different sustainability issues were seen as particularly relevant at different stages of the telecentre lifecycle. Both Akshaya and eSeva projects have commercial services (e.g., utility bill payment) and noncommercial services (e.g., information), and it is reflected in the literature that the commercial model is better for financial sustainability and the non-commercial or social model fosters social capital (Toyama \& Kuriyan, 2007; Meddie, 2006). Based on our results, we conclude that the social capital model can be added to the commercial enterprise model at the maturity stage of the telecentre lifecycle because financial sustainability can be ascertained with commercial services. When the centres are financially sustainable, additional social capital services may be included. Also, a mechanism should be devised by the entrepreneurs to fix costs for such services given that most entrepreneurs studied have difficulty in setting the price for non-commercial services.

This study, though set in India, has a global reach. Telecentre-based projects are implemented in many parts of the world, and most of them focus on empowering citizens. The findings of this research have policy implications in terms of the way government services are designed and delivered through telecentres in developing countries. Thus, learnings from this study may also be useful in the implementation of telecentre projects in other parts of the world.

\section{About the Authors}

Gaurav Mishra is an Assistant Professor in the Institute of Management at Nirma University in Ahmedabad, India. Before joining Nirma University, he was associated with the Development Management Institute in Patna and the Dhirubhai Ambani Institute of Information and Communication Technology in Gandhinagar as Assistant Professor. He also worked with International Crops Research Institute for the Semi-Arid tropics (ICRISAT), Hyderabad in the Knowledge Management and Sharing department. He received his $\mathrm{PhD}$ from the University of Reading, United Kingdom. His thesis focused on understanding adoption, social Inequality, and development impact with respect to e-government centres in rural India. He also holds an MS degree from Dhirubhai Ambani Institute of Information and Communication Technology.

Balakrishnan Unny $\mathbf{R}$ is currently pursuing his $\mathrm{PhD}$ in the area of software project management from the National Institute of Technology, Tiruchirappalli (NIT Trichy) in Tamil Nadu, India. He has over 10 years of experience in academia and consulting in the area of IT and risk. He has executed projects in information security, business continuity, IT risk, and IT process improvements. Prof. Balakrishnan also has experience working in projects across multiple domains including financial markets, telecommunications, and IT service provision. He holds an MBA from the University of Sheffield, United Kingdom, with a specialization in IT and risk management.

\section{References}

Barkley, D. L. 2006. The Value of Case Study Research on Rural Entrepreneurship: Useful Method. Paper presented at the Joint ERSRUPRI Conference on Exploring Rural Entrepreneurship, October 26-27, 2006, Washington, DC.

Bhatnagar, S. 2003. The Economic and Social Impact of EGovernment. A Background Paper for the Proposed UNDESA World Public Sector Report: E-Government the Citizens and the State: Debating Governance in the Information Age. Ahmedabad, India: Indian Institute of Management, Ahmedabad.

Charmaz, K. 1990. 'Discovering' Chronic Illness: Using Grounded Theory. Social Science \& Medicine, 30(11): 1161-1172. http://doi.org/10.1016/0277-9536(90)90256-R

Creswell, J. W. 2002. Educational Research: Planning, Conducting, and Evaluating Quantitative. Upper Saddle River, NJ: Prentice Hall. 


\section{Understanding the Role of Rural Entrepreneurs in Telecentre Sustainability}

\section{Gaurav Mishra and Balakrishnan Unny $R$}

Fuchs, R. P. 1998. If You Have a Lemon, Make Lemonade: A Guide to the Start-Up of the African Multipurpose Community Telecentre Pilot Projects. Ottawa: Future Works Inc. http://hdl.handle.net/10625/14740

Gaiani, S., Hansson, H., Meegammana, N., \& Mozelius, P. 2009. Critical Issues for E-Learning Telecentres in Sri Lanka and India. In Proceedings of the 23rd ICDE World Conference on Open Learning and Distance Education including the 2009 EADTU Annual Conference, June 7-10, 2009. Maastricht, The Netherlands: Open Universiteit Nederland.

Geldof, M., \& Unwin, T. 2005. Becoming an Information Society: The Role of New IT in Development. Steyning, United Kingdom: Wilton Park.

Gilbert, M. R., Masucci, M., Homko, C., \& Bove, A. A. 2008. Theorizing the Digital Divide: Information and Communication Technology Use Frameworks among Poor Women using a Telemedicine System. Geoforum, 39(2): 912-925.

http://doi.org/10.1016/j.geoforum.2007.08.001

Gopakumar, K. 2006. E-Governance Services through Telecentres Role of Human Intermediary and Issues of Trust. In Proceedings of the International Conference on Information and Communication Technologies and Development (ICTD'06): 131-142. http://doi.org/10.1109/ICTD.2006.301850

Harris, R. W., Kumar, A., \& Balaji, V. 2003. Sustainable Telecentres? Two Cases from India. In S. Madon \& S. Krishna (Eds.), The Digital Challenge: Information Technology in the Development Context: 124-135. London: Routledge.

IIITB. 2005. Information and Communication Technologies for Development: A Comparative Analysis of Impacts and Costs from India. Bangalore, India: Indian Institute of Information Technology, Bangalore (IIITB).

Kuriyan, R., \& Toyama, K. (Eds.) 2007. Review of Research on Rural PC Kiosks. Microsoft Research India, University of California, Berkeley, and London School of Economics.

Levie, J., \& Lichtenstein, B. B. 2010. A Terminal Assessment of Stages Theory: Introducing a Dynamic States Approach to Entrepreneurship. Entrepreneurship Theory and Practice, 34(2): 1207-1227.

http://doi.org/10.1111/j.1540-6520.2010.00377.x

Madon, S. 2004. Evaluating the Developmental Impact of Egovernance Initiatives: An Exploratory Framework. The Electronic Journal of Information Systems in Developing Countries, 20(1): $1-13$.

http://doi.org/10.1002/j.1681-4835.2004.tb00132.x

Meddie, M. 2006. Rethinking Telecentre Sustainability: How to Implement a Social Enterprise Approach - Lessons from India and Africa. Journal of Community Informatics, 2(3): 45-57.

Meng, C. C., Samah, B. A., \& Omar, S. Z. 2013. A Review Paper: Critical Factors Affecting the Development of ICT Projects in Malaysia. Asian Social Science, 9(4): 42. http://doi.org/10.5539/ass.v9n4p42
Mercer, C. 2005. Telecentres and Transformations: Modernizing Tanzania through the Internet. African Affairs, 105(419): 243-264. http://doi.org/10.1093/afraf/adi087

Misund, G., \& Høiberg, J. 2003. Sustainable Information Technology for Global Sustainability. Paper presented at the Digital Earth in Information Resources for Global Sustainability Symposium, Brno, Czech Republic.

Morelli, N. 2003. Product-Service Systems, a Perspective Shift for Designers: A Case Study: The Design of a Telecentre. Design Studies, 24(1): 73-99. http://doi.org/10.1016/S0142-694X(02)00029-7

Mukerji, M. 2008. Telecentres in Rural India: Emergence and a Typology. The Electronic Journal of Information Systems in Developing Countries, 35(1): 1-13. http://doi.org/10.1002/j.1681-4835.2008.tb00242.x

Pade, C. I., Mallinson, B., \& Sewry, D. 2006. An Exploration of the Categories Associated with ICT Project Sustainability in Rural Areas of Developing Countries: A Case Study of the Dwesa Project. In Proceedings of the 2006 Annual Research Conference of the South African Institute of Computer Scientists and Information Technologists on IT Research in Developing Countries: 100-106. Somerset West, South Africa: South African Institute for Computer Scientists and Information Technologists. http://doi.org/10.1145/1216262.1216273

Proenza, F. J. 2001. Telecenter Sustainability-Myths and Opportunities. The Journal of Development Communication, 12(2): 94-109.

Rao, S. S. 2008. Social Development in Indian Rural Communities: Adoption of Telecentres. International Journal of Information Management, 28(6): 474-482.

http://doi.org/10.1016/j.ijinfomgt.2008.01.001

Roman, R., \& Colle, R. D. 2002. Themes and Issues in Telecentre Sustainability. Working Paper No. 10. Manchester, United Kingdom: Institute for Development Policy and Management, University of Manchester.

Samik-Ibrahim, R. M. 2000. Grounded Theory Methodology as the Research Strategy for a Developing Country. Forum: Qualitative Social Research, 1(1). http://doi.org/10.17169/fqs-1.1.1129

Sey, A., \& Fellows, M. 2009. Literature Review on the Impact of Public Access to Information and Communication Technologies. Center for Information \& Society Working Paper No. 6. Seattle, WA: University of Washington.

Sigweni, B., Mangwala, M., \& Ayoung, D. A. 2017. Factor Subset Selection for Predicting Sustainability of a Telecentre Using CaseBased Reasoning. In Proceedings of AFRICON 2017: 536-541. Cape Town, South Africa: IEEE. http://doi.org/10.1109/AFRCON.2017.8095538

Tschang, T., Chuladul, M., \& Le, T. T. 2002. Scaling-Up Information Services for Development: A Framework of Increasing Returns for Telecentres. Journal of International Development, 14(1): 129-141. http://doi.org/10.1002/jid.865 


\section{Academic Affiliations and Funding Acknowledgements}

Canadà
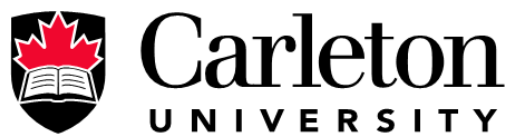

U N I V E R S I T Y

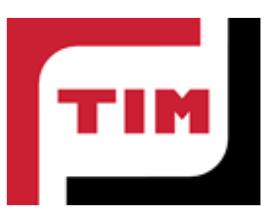

The Federal Economic Development Agency for Southern Ontario (FedDev Ontario; feddevontario.gc.ca) is part of the Innovation, Science and Economic Development portfolio and one of six regional development agencies, each of which helps to address key economic challenges by providing regionallytailored programs, services, knowledge and expertise.

- The TIM Review receives partial funding from FedDev Ontario's Investing in Regional Diversification initiative.

Technology Innovation Management (TIM; timprogram.ca) is an international master's level program at Carleton University in Ottawa, Canada. It leads to a Master of Applied Science (M.A.Sc.) degree, a Master of Engineering (M.Eng.) degree, or a Master of Entrepreneurship (M.Ent.) degree. The objective of this program is to train aspiring entrepreneurs on creating wealth at the early stages of company or opportunity lifecycles.

- The TIM Review is published in association with and receives partial funding from the TIM program. 